\title{
Giro cultural y estudios de juventud en el chile contemporáneo: crisis de hegemonía, mediaciones y desafíos de una propuesta
}

\author{
Raúl Zarzuri C. \\ Rodrigo Ganter S. ${ }^{2}$
}

\section{RESUMEN}

La perspectiva cultural o lo que se ha llamado el "giro cultural" en los estudios sobre los jóvenes y juventudes en Chile, y el uso de algunas categorías conceptuales como neotribalización o tribus urbanas, han sido objeto de discusiones desde los inicios del nuevo siglo. En general, las respuestas a estas críticas no han sido dadas. El presente artículo, intenta elaborar una respuesta a esas críticas, señalando el contexto que lleva a elaborar la propuesta; los hitos de ese giro e intentar realizar un balance sobre lo que se ha denominado: el balance del proceso de neotribalización en la postdictadura en nuestro país. Posterior-

1 Doctor $\odot$ en Educación y Sociólogo (Universidad Academia de Humanismo Cristiano, Santiago, Chile). Magíster en Antropología y Desarrollo (Universidad de Chile). Profesor de la Escuela de Sociología de la Universidad Academia de Humanismo Cristiano y coordinador del NTI: "Jóvenes y Militancias Políticas en el Chile Actual: rupturas y continuidades" de la misma universidad. Investigador del Centro de Estudios Sociales y Culturales (CESC). Correo electrónico: rzarzuri@ gmail.com.

2 Sociólogo (Universidad ARCIS, Santiago, Chile). Doctor en Estudios Urbanos (Pontificia Universidad Católica de Chile). Investigador Responsable Proyecto "Prácticas y Relatos de lo Corporal en Jóvenes Urbanos de las Ciudades de Concepción y Santiago" (Fondecyt $\mathrm{n}^{\circ}$ 11140866). Docente e Investigador del Departamento de Sociología, Universidad de Concepción. Coordinador del Grupo de Trabajo Juventudes de la Red Iberoamericana de Investigación en Imaginarios y Representaciones Sociales. Correo electrónico: rganter@udec.cl. 
mente, se señala, que los conceptos que se utilizaron para dar cuenta de las prácticas juveniles no obedecieron a un efecto de fascinación sino a un efecto de mediación cultural e histórica que permitió realizar un enlace generacional, para cerrar con algunas pistas del rendimiento de la perspectiva culturalista y sus desafíos.

PALABRAS CLAVES: JÓVENES, CULTURAS JUVENILES, GIRO CULTURAL, TRIBUS URBANAS

\section{VIRADA CULTURAL E ESTUDOS DE JUVENTUDE NO CHILE CONTEMPORÂNEO: CRISE DE HEGEMONIA, MEDIAÇÕES E DESAFIOS DE UMA PROPOSTA}

\section{RESUMO}

A perspectiva cultural ou o que é chamado de "virada cultural" nos estudos sobre os jovens e juventudes no Chile, e o uso de algumas categorias conceituais como neotribalização ou tribos urbanas, foi objeto de discussões desde o início do novo século. Em geral, as respostas a estas críticas não foram dadas. Este artigo, tenta elaborar uma resposta para essas críticas, apontando o contexto que leva a elaborar a proposta; os marcos históricos mais importantes dessa virada e tentar equilibrar o que é denominado: o balanço do processo de neotribalização na pós-ditadura em nosso país. Posteriormente, é mostrado que os conceitos que foram utilizados para explicar as práticas juvenis não se deviam a um efeito de fascinação se não que a um efeito de mediação cultural e histórica que permitiu realizar uma conexão geracional, para finalizar com algumas pistas do desempenho da perspectiva culturalista e seus desafios.

PALAVRAS-CHAVE: JOVENS, CULTURAS JUVENIS, VIRADA CULTURAL, TRIBOS URBANAS 


\title{
CULTURAL TWIST AND YOUTH STUDIES IN CONTEMPORARY CHILE: CRISIS OF HEGEMONY, MEDIATIONS AND THE CHALLENGES OF A PROPOSAL
}

\begin{abstract}
The cultural perspective, also called "cultural twist" in the studies on youngsters and youths in Chile, and the use of certain conceptual categories such as neotribalism or urban tribes, have been discussed since the beginning of the new century. In general, the criticism raised from such discussions have not been properly answered so far. The present article, hence, aims to provide them, pointing out the context leading to elaborate such proposal and its landmarks, in an attempt to balance the post-dictatorship neotribalism process in our country. Later, as stated, the concepts used to show those youth practices did not address a fascination effect but an effect of cultural and historical mediation that allowed a generational link, to conclude with hints on the performance of the culturalist perspective and its challenges.
\end{abstract}

KEYWORDS: YOUNG PEOPLE, YOUTH CULTURES, CULTURAL TWIST, URBAN TRIBES 
resos que creen saberlo todo

$r$ dan solucionesy palabrasy cifras

Pregúntales que hacen cuando cierran sus libros

Pregúntales que hacen cuando llegan los cambios

r con eso, ¿queé? ¿Acaso es esto revolución?

Emociones Clandestinas, 1987

\section{CUATRO ELEMENTOS QUE CONSIDERAR EN EL GIRO HACIA LA CUL- TURA}

A finales de los años 9o', quienes escriben este artículo, nos encontrábamos analizando el derrotero, que hasta esa época habían realizado los llamados "estudios sobre los jóvenes", constatando cuatro cosas que a nosotros nos parecían centrales.

La primera, la clausura de los estudios sobre juventud, tal como se venían desarrollando desde inicios de los años 8o', y consecuentemente el debilitamiento del campo y las condiciones para problematizar lo social desde lo juvenil. Se constataba que la publicación de artículos u otros textos se había detenido. Anteriormente hubo una proliferación de artículos y libros, entre los cuales se destaca: "Juventud chilena. Razones y subversiones" (Agurto; Canales, De la Maza, I985); "La rebelión de los Jóvenes (Valenzuela, I985); "Jóvenes: una conversación social por cambiar" (Cottet y Galván, r993); "Juventud urbana y exclusión social" (Undiks, 1990), "Los jóvenes pobladores en las protestas nacionales (I983-1984)" (Weinstein, I988), todos los documentos publicados por ECO Comunicaciones sobre la juventud popular chilena en su serie "Educación y Solidaridad", por mencionar solo algunos textos relevantes que inundaron los ochentas intentando entender a los jóvenes (populares) de esos años, los cuales configuraron y relevaron un tipo de juventud. Como señala Zarzuri (2005), los jóvenes de los ochenta y principios de los noventas fueron definidos y estudiados:

(...) Como urbano-populares en medio de las protestas, por lo tanto, con imágenes de rebeldes, anómicos o con posibilidades de construcción de movimiento social (Gonzalo de la Maza, Irene Agurto, José Weinstein, Manuel Canales, Domingo Asún, Eduardo Valenzuela) y comenzando los noventa, como jóvenes con deuda social (Pablo Cottet, Klaudio Duarte, Dionisios Seussus,

3 Ver entre otros los siguientes documentos: Agurto, Irene y De la Maza, Gonzalo: "La juventud popular: elementos para comprenderla" (1984). Documento de trabajo $\mathrm{N}^{\circ} 6$, Serie Movimiento Popular: “Los Jóvenes pobladores: organización y política (1984b)". Documento de trabajo $\mathrm{N}^{\circ} 7$, Serie Movimiento Popular: "Subjetividad juvenil popular en Chile hoy" (1984c). Agurto, Irene (1984d) Documento de trabajo $\mathrm{N}^{\circ} 8 \mathrm{y}$, "Notas para un movimiento juvenil popular" Documento de trabajo $\mathrm{N}^{\circ} 11$. 
Undik en. Alt, Mario Sandoval). Otras aproximaciones, provenían desde ejes temáticos como la educación, la sexualidad, la drogadicción, por nombrar algunos. (p.II)

Una segunda cuestión, es que el análisis que veníamos realizando sobre la producción de lo que podríamos llamar "una teoría incipiente sobre las juventudes chilenas" nos mostraba que ella había quedado atrapada en visiones reduccionistas y totalizantes que daban a la estructura (social u económica) una determinación en la configuración en las modalidades de ser joven; en sus construcciones identitarias. Si bien, se rescataban procesos de construcción de subjetividades y de sujetos, éstos estaban constreñidos por esa estructura, o sea, no tenían ninguna posibilidad de realizar un punto de fuga por fuera de las explicaciones binarias, sobre las complejas, plurales y dinámicas condiciones existenciales en que una mayoría de jóvenes chilenos se encontró en toda la dictadura y bien entrado el período de normalización e institucionalización hacia la democracia.

Habría que señalar, que precisamente, y como siempre ocurre en nuestras ciencias sociales, las miradas que se tuvieron estaban mediadas por un contexto, el de la dictadura cívico-militar imperante, que rescató y visibilizó -homogéneamente- a un cierto tipo de jóvenes, etiquetándolos como jóvenes populares; jóvenes dañados psicosocialmente, en riesgo social, jóvenes con los cuáles se tenía una deuda social. Para esos jóvenes, se diseñó lo poco y nada que se ha tenido de políticas públicas sobre juventud en nuestro país.

¿De qué adolecieron estas miradas? No consideraron y no pudieron ver, por el llamado efecto paradigma (Kuhn, 2004), a las otras juventudes que en esa misma época comenzaron a proliferar por los entramados intersticiales de nuestras ciudades4. Así, en esos mismos años cuando se visibilizaba a los "jóvenes populares", habían emergidos y proliferados una serie de prácticas culturales juveniles, asociadas a lo que se denominó "estilos juveniles" (Feixa, 1998). Como señala Contreras, Guajardo y Zarzuri (2005) respecto de esta situación:

Sin embargo, por abajo -lo que podríamos llamar el underground-, se cobija una fuerte manifestación musical juvenil, ligada al rock progresivo y/o pesado, que se constituye en otro elemento constructor de identidad. Grupos como Tumulto, Pozitunga, Arena Movediza entre otros mantienen la alicaída escena rockera de esa época, apartándose en palabras de Fabio Salas del "culto terrible al dolor" en que cayó el Canto Nuevo. En relación a esto, Cesar Albornoz señala por ejemplo a Tumulto y su famosa canción "Rubia de los ojos azules", canción que "nos hablaba de un extraño amor nocturno que bien podía ser un desbutal; nada

4 En los años ochenta a pesar de la dictadura, florecen experiencias de prácticas culturales juveniles que no son consideradas en los estudios sobre la juventud de esa época. A principios de los años ochenta, aterriza el New Wave y el el Brit Pop, El pop chileno y el rock latino. El Break Dance hace su aparición el año 1984 y de ahí deriva al hip-hop posteriormente. El Punk emerge entre los años 1984/85. Del mismo modo, la cultura negroide emerge en esas fechas en cualquiera de sus manifestaciones (Emo/Gótico/Dark). La escena heavy metalera comienza a cobrar vigencia. 
de Chile o patria o pueblo o revolución, simplemente 'caminar por la vida sin prisa'. (p. 26)

Un tercer elemento asociado al punto anterior dice relación, con que, salvo algunas excepciones, la mirada desde la estructura venía acompañada de un despliegue teórico que la situaba en lo que se ha denominado el estructural funcionalismo. En ese marco interpretativo (paradigma), se recurría a los conceptos de "anomia", "conducta desviada", "desintegración social" (Durkheim, 2012) como ejes para entender las prácticas juveniles de esos años. Demás está decir que eso todavía sigue predominando.

Así, en una serie de artículos y posterior libro que escribimos ${ }^{5}$, señalábamos que la utilización de esos conceptos suponía un "ejercicio conceptual extremista", en el sentido que no había ninguna posibilidad de realizar una lectura más "comprensiva" y menos binaria de las prácticas culturales juveniles que estaban apareciendo, ya que de forma casi automática se tenía que aplicar las conceptualizaciones o categorías señaladas anteriormente. De esta forma, el new wave, el punk, el graffiti hip-hop, las culturas negroides (emos, dark y góticos), por nombrar algunas, eran vistas como conductas desviadas, por lo tanto, peligrosas para el orden social imperante, cuestión que conducía a su vigilancia. Frente a esto, instalamos la crítica, señalando: "que la situación de los jóvenes en la sociedad no puede ser reducida a un mecanismo de integración funcional, sino que se requiere el reconocimiento de la existencia de un sujeto particular que se identificaría con orientaciones culturales generales y con convicciones personales y colectivas ligadas a su propio quehacer." (Zarzuri y Ganter, 2002, p.37) y, por lo tanto, si acudíamos a otros enfoques, como por ejemplo el enfoque subcultural, teníamos que asumir que la distinción entre desviado o no desviado dependía de situaciones contingentes en las cuales los jóvenes estaban instalados. Por lo tanto, no era posible determinar a priori lo que era una conducta normal o desviada, "sin conocer las reglas de interacción social y dónde se encuentran los individuos dentro de la interacción, ya que estos pueden cambiar las reglas unilateralmente o como el producto de la acción del grupo de pertenencia" (Zarzuri, 200I, p. 12).

Junto a todo lo señalado anteriormente, hay una cuarta cuestión que se hace imprescindible enfatizar para entender cómo llegamos a situarnos en lo que se ha denominado la episteme culturalista y el giro cultural que empujamos -pensamos con éxito- al interior de los estudios de juventud en nuestro país, logrando configurar -intergeneracionalmente- una comunidad hermenéutica. Esto está vinculado con nuestras propias trayectorias biográficas y adscripciones identitarias, que más que gravitar de modo exclusivo en torno al mantra de la clase social, se estructuraron -relacionalmente- en función de militancias culturales y generacionales específicas, históricamente delimitadas, y espacio-territorialmente situadas, que fueron definiendo -porosamente- un devenir

5 Ver: Zarzuri, R. \& Ganter, R. (2002) Culturas Juveniles, Narrativas Minoritarias y Estéticas del descontento.Santiago de Chile: Ediciones Universidad Raúl Silva Henríquez. 
investigador, explorador inductivo, observador participante y también activista, etc. de fuerte vocación e impulso dialógico y etnográfico (Guber, 20II), por lo mismo capaz reconocer -éticamente y simétricamente- el espesor y la reflexividad (Bourdieu \& Waquant, 2008) del "otro" generacional, no bajo la "lógica extractivista" del informante clave, sino como compañero/a epistémico/a, compañero/a de viaje, al cual se le acompaña a través de la ciudad y sus intersticios, construyendo -colaborativamente- mapas nocturnos y existenciales, elaborando recíprocamente preguntas sobre la genealogía del Chile actual. Aspectos que se reflejan de modo sustantivo en el estudio pionero -quizá- el más emblemático que emprendiéramos junto al colectivo juvenil hip hop Legua York ${ }^{6}$ iniciando el siglo XXI, y donde ya "augurábamos" los signos de lo que sería la revuelta "pingüina" del año 2006; en nuestro caso, un antes y un después en materia de co-aprendizajes en el campo de los estudios de juventud, y en una histórica población de la zona centro sur de Santiago: La Legua.

Habría que señalar que el tema de las biografías que portamos como investigadores no es un dato menor, ya que ella estructura lo que observamos, lo que estudiamos y las propias estrategias y tácticas que escenificamos para generar conocimiento. Así, no solo el pasado social sino también el pasado cultural (las adscripciones identitarias) son claves determinantes cuando se trata de hacer investigación. Como señala Alfredo Nateras (2014) leyendo a Bourdieu: "se trata de tener presente la necesidad de explorar el inconsciente social del sociólogo (o, antropólogo): realizar la sociología de la sociología en la aspiración de fundamentar una epistemología de y en las ciencias sociales." (p.I49)7.

Es en este contexto descrito en páginas anteriores, que nos situamos a finales de los años noventa para intentar levantar una propuesta de investigación que permitiera rescatar y visibilizar las prácticas culturales que comenzaron a emerger a principios de los años 80'y que explosionaron en los 9o' y principios del nuevo siglo en el marco de la llegada de la llamada "democracia transicional".

Así, situados en una experiencia que nos era conocida (habíamos vivido y militado culturalmente) como era la emergencia de las culturas juveniles en nuestro país, concepto que tomamos de Carles Feixa (1998), utilizamos otros conceptos que también podrían dar cuenta de esa emergencia producto de otras lecturas, comenzando a utilizar el concepto de "tribu urbana" siguiendo a Maffesolli (I988) o como lo señalamos en el libro que escribimos el año 2002, acuñamos conceptos como: "narrativas minoritarias"; "estéticas del descontento" o "caleidoscopios de la cotidianeidad". En ese sentido, para nosotros los

6 Nos referimos al libro "Culturas Juveniles, Narrativas Minoritarias y Estéticas del Descontento", $\mathrm{UCSH}, 2002$.

7 Ver el capítulo V: "De los mapas teóricos, a los territorios metodológicos: ¿el investigador: dato etnográfico?" En: A, Nateras. (2014). Vivo por mi madre y muero por mi barrio. Significados de la violencia y la muerte en el Barrio 18 y la Mara Salvatrucha. SEDESOL: INJUVE \& UAM, Iztapalapa. México. 
conceptos eran intercambiables y debían ser entendidos como metáforas que nos permitían puntos de fuga de las miradas estigmatizantes y tradicionales.

\section{EL GIRO HACIA LAS CULTURAS JUVENILES EN LOS ESTUDIOS DE LOS JÓVENES Y JUVENTUDES EN CHILE}

En nuestro país, el giro hacia la cultura como eje de análisis de las prácticas juveniles, comienza tímidamente a mediados de los años noventa, cuando Contreras (I996) en su tesis de antropología analiza el carrete juvenil como rituales que permiten la construcción de identidades sustitutivas o de emergencia en medio de sociedades altamente competitivas. Esto es complementado con la aparición de la Revista Proposiciones $\mathrm{N}^{\circ} 27$ (I996) editada por SUR Profesionales, donde se replica el artículo de Contreras y un interesante artículo sobre el consumo de drogas titulado: "El silencio de los angustiados" escrito por Sepúlveda, Pérez y Gaínza (I996) quienes plantean que hay que mirar los consumos de drogas "desde adentro", cartografiando su itinerancia y señalando que, "el conocimiento del universo-pasta nos refiere a una aventura en la cual nuestra participación de ese mundo de vida es cognitivamente ineludible." (p.73). El número en cuestión es un fiel reflejo de un proceso de transición que estaban viviendo los estudios de juventud en nuestro país, ya que, junto con estos artículos que responden a la perspectiva que llamamos culturalista (son solo dos), la gran mayoría (siete en total) responde más a preocupaciones tradicionales (equidad, pobreza extrema, integración social, trabajo, educación técnico profesional, entre otros).

Sin embargo, el primer texto que da un giro en el análisis de los jóvenes chilenos es el artículo publicado por Martín Hopenhayn el año i997, titulado: "Nuclearse, resistirse, abrirse: las tantas señales en la identidad juvenil"8, el cual realiza una entrada novedosa al campo de los estudios sobre jóvenes en nuestro país. Las ideas centrales que pone en circulación parten por analizar el fenómeno de la exclusión que viven los jóvenes, pero apartándose de la mirada tradicional, donde la estructura constriñe a los jóvenes. Para el autor, los jóvenes urbanos enfrentan un escenario complejo, pero para enfrentarlo tienen otras posibilidades como: "crear identidades grupales, fusionarse en intersticios y márgenes, revertir la naturaleza del sistema por los bordes, los huecos, las transgresiones cómplices y casi tribales." (I997, p.I4). Lo que se está impugnando señala el autor, es la racionalización de la vida moderna, el disciplinamiento en el trabajo y la regimentación del cuerpo. (I997, p. I4). Así, señala Hopenhayn:

La fusión neotribal vuelve con otro sentido, como repulsa y protesta contra un orden que prescribe la identificación con el status quo, pero también

8 Texto publicado en la Revista Chilena de Temas Sociológicos $\mathrm{N}^{\circ} 3$ (1997) de la Universidad Católica Blas Cañas. 
como experiencia expansiva en esa misma protesta. [... El El recurso de la transgresión implica una propuesta contestataria: la distancia crítica se revierte en efusividad del desborde. No importa la falta de agudeza siempre que el derrame emocional sea una evidencia experiencial más que una propuesta, y que la transgresión sea afirmativa por la irrecusable explosión que provoca la subjetividad. (I997, pp. I4-I5)

El desmarque de Hopenhayn es notorio con las miradas que hasta esa época se articulaban, cuestión que no está exenta de complejidades. Así, la estructura, si bien juega un papel importante, no supone una camisa de fuerza para la construcción de formas de sociabilidad y de construcción de identidades por parte de los jóvenes. Serán formas provisorias, débiles, pero conforman un entramado que permite el sostén en situaciones de precariedad material y de sentido.

Posteriormente aparecerán los textos que los autores de este artículo escribieron a finales de los años noventa y principios del nuevo siglo, producto de la lectura de Michel Maffesoli, Carles Feixa, la Escuela de Estudios Culturales de Birminghan y autores post estructuralistas, entre otros, y que van a entregar teóricamente otra mirada para intentar recorrer las juventudes chilenas desde los ochenta hasta ahora, utilizando la perspectiva culturalista para mirar otras realidades juveniles. Reflejo de esto es la etapa inicial de escritura en conjunto, que parte el año I997, con el articulo:" Tribus Urbanas: por el devenir cultural de nuevas socialidades juveniles", seguido por "Culturas juveniles y micropolíticas del afecto" (2000) y la publicación del libro "Culturas Juveniles, Narrativas Minoritarias y Estéticas del descontento (2002), quizás texto señero para algunas generaciones que entraron al estudio de las culturas juveniles, y donde con la excusa de mirar dos escenas juveniles como el hip-hip (que por primera vez era estudiado) y el punk, se desarrolla una entrada crítica desde la perspectiva cultural, cuestión que permitió entrar en el análisis de la memoria como resistencia a partir del análisis semántico de las letras de las canciones de la Legua York e introduciendo teóricamente por primera vez la afectividad como eje constitutivo de las nuevas socialidades juveniles que permeaban nuestra ciudades, hoy transformada en un interesante objeto de estudio, a partir de una apuesta particular: una socio-antropología de los afectos.

Posteriormente, otros artículos, pero está vez escrito por separado, se sumaron a la constitución de la nueva escena que daría pie al enfoque de las culturas juveniles o al giro culturalista. El primero escrito el 2000 publicado en la Revista Última Década de Zarzuri titulado: "Notas para una aproximación teórica a nuevas culturas juveniles: las tribus urbanas", y los de Ganter: "Graffiti, Descolonización y Escrituras en Fuga" (2002) y "De Cuerpos Urbanos, Tatuajes y Culturas Juveniles". (2005) ${ }^{9}$ y "Cuerpos Suspendidos: Cartografías e Imagina-

9 Ambos artículos publicados en la Revista Chilena de Temas Sociológicos de la Universidad Católica Blas Cañas. 
rios de la Piel en Jóvenes Urbanos Chilenos". ${ }^{\circ}$

Este pequeño paneo sobre la escena culturalista no puede dejar de lado dos autores y un espacio, que ha realizado aportes substanciales a los estudios sobre las prácticas juveniles. El primero es Christian Matus quién retoma los estudios sobre el carrete juvenil, situando sus estudios en el divertimento juvenil en espacios de la ciudad, como bares, la discoteque Blondie y el Barrio Bellavista (I999; 200I a y b; 2000; 2002; 2004 y 2007) o asociados al campo de las sexualidades juveniles (2005). El segundo autor es Yanko González, uno de los pocos investigadores que se ubica fuera de Santiago, para ser específico, en la Universidad Austral de Chile en Valdivia, quien ha intentado, a nuestro parecer, recoger una historia cultural de los jóvenes a través de innumerables textos, entre los cuales destacan: "El "Golpe Generacional” y la Secretaría Nacional de la Juventud: Purga, Disciplinamiento y Resocialización de las identidades juveniles bajo Pinochet (1973-1980)." (2015); Genesis of Youth Cultures in Chile: Coléricos \& Carlotos (1955-1964)" (2012); "Primeras culturas juveniles en Chile: Pánico, malones, pololeo y matiné" (20II); "Sumar y no ser sumados: culturas juveniles revolucionarias, mayo de 1968 y diversificación identitaria en Chile" (2010) entre otros.

Por otro lado, el centro que ha aglutinado de forma ininterrumpida, aunque muchas veces de forma intermitente en su producción, es el Centro de Estudios Sociales y Culturales (CESC) ${ }^{\text {II }}$, que fue formado por quienes escriben y otros colegas en el año 2002. Ha sido el espacio dialógico donde la perspectiva culturalista se ha asentado y ha intentado diseminarla, realizando una producción pequeña de artículos y con experiencia de investigación. Ahí una serie de investigadores/as durante el inicio del nuevo siglo ${ }^{12}$ realizaron colaborativamente parte de sus investigaciones y aportaron en áreas que tienen que ver con prácticas culturales como el graffiti; las relaciones culturas juveniles y escuela; el análisis de los movimientos juveniles y la construcción de ciudadanías juveniles; las prácticas de visualización pasando desde la televisión de los 9o's/200o a las redes y las multipantallas; las nuevas configuraciones de ser joven; la participación políticas y nuevas formas de politicidad juvenil; nuevas

10 Ver: Revista Polis, 4(11). , Santiago de Chile: Universidad Bolivariana.

11 Ver página web: www.cesc.cl.

12 Entre otros/as: Tamara Contreras, Gricelda Figueroa, Carolina Benavente, Sergio Guajardo, Vanessa Goecke, Nicolas del Valle, quienes aportaron una serie documentos que publico el CESC en esa época, entre ellos: Benavente, C. \& Figueroa, G. (2005): “La deserción simbólica. Cultura juvenil y educación: perspectivas para un diálogo pendiente"; Contreras, T. (2005) "Una Aproximación a la producción intelectual en torno a la temática de los estudiantes secundarios contemporáneos. Un Balance Bibliográfico" (2005); Zarzuri, R.; Contreras, T. \& Guajardo, S. (2006) “¿Movimientos sociales o colectivos juveniles? aportes teóricos para una discusión"; Zarzuri, R.; Contreras, T. \& Guajardo, S. (2006) "Identidad, participación e hitos de resistencia juvenil en Chile durante el siglo XX."; Jara, L. "Del malón al carrete" (2004); Hidalgo, A.; Silva, P. \& Lecourt, Y. (2005) "Secreto a voces. afectos y sexualidades en mujeres jóvenes con orientación sexual hacia ambos sexos"; Goecke, V. (2005) "Juventud y política revolucionaria en Chile en los sesenta”. 
forma de militantismos juvenil, son algunos de los temas, que sigue desarrollado el centro hasta ahora.

\title{
3. BALANCE SOBRE EL GIRO CULTURAL Y EL CONCEPTO DE NEOTRI- BALIZACIÓN JUVENIL EN EL CHILE DE LA POSTDICTADURA: ¿FASCI- NACIÓN, INVISIBILIZACIÓN O MEDIACIÓN GENERACIONAL?
}

\author{
"El hip hopy mi ser mapuche \\ no son antagonistas, son complementarios. Todo fue como un rompecabezas cuyas piezas \\ encajaban. Creo que esa cultura me rescató porque, de lo contrario, habría terminado \\ pegándome unos pipazos en la esquina. \\ Para mí (...) la cultura hip hop, es hacer escuela. \\ Es tradición oral. \\ En la cultura mapuche es muy parecido. Cuando uno se junta en la ruka, a tomar mate, \\ a conversar, en el fondo, es como un taller hip hop. \\ Hacer nütram es educarte" \\ Gonzalo Luanko, 20I5
}

En este punto queremos aclarar, aunque desborda los objetivos de este texto, que lo que se denominó teóricamente en los años 90 ` como giro cultural en los estudios de juventud chilenos, se encontraba -y se encuentra todavía- fuertemente anclado con la perspectiva desarrollada por los Estudios Culturales Británicos, particularmente con el pensamiento de Raymond Williams (2003) y su lógica híbrida y relacional para aproximarse a la cultura, esto es, cómo los agentes sociales y los grupos humanos pueden desafiar significados, negociar sentidos, interactuar y modificar activamente sus condiciones materiales y simbólicas de existencia. En el caso chileno, a nuestro juicio, este giro no incluyó únicamente preguntas y búsquedas intelectuales centradas en los procesos de neotribalización juvenil y sus estilos espectaculares, sino que incluyó una inflexión en la agenda de investigación mucho más amplia, heterodoxa y a ratos difusa, y cuyo interés -por momentos- se hacía más visible y localizable en los espacios de ocio y en el tiempo libre juvenil, como por ejemplo, las cuestiones asociadas con las pasiones deportivas y las llamadas barras bravas, la socialidad presente en los grupos de esquina, el consumo ritual de sustancia ilícitas, lo corporal como territorio político, la diversidad sexual y el nomadismo afectivo, las prácticas circenses y el malabarismo callejero, el consumo cultural y de medios, las denominadas pandillas juveniles y sus manifestaciones territoriales, la bohemia juvenil, el activismo de los colectivos micro-políticos, etc. (Hopenhayn, I997, Recasens, I999, Cottet, I993, Contreras, I996, Matus, 2000, Sepúlveda, I996, entre otros).

Sin embargo, hay que reconocer que el llamado giro cultural, que como se describió anteriormente tiene una alta densidad teórica, se asoció, tanto en 
nuestro país como en el resto de América latina, a un concepto acuñado por el sociólogo francés Michel Maffesoli denominado neotribalismo, del cual los medios de comunicación recogen y amplifican el concepto de tribu urbana, para dar cuenta de ciertas expresiones juveniles denominadas espectaculares en relación con su estética y que permitía describir prácticas emergentes de sociabilidad juvenil. Sin embargo, hay que aclarar que el concepto de neotribalización es una perspectiva de análisis teórico más profunda que trasciende a los estudios de los jóvenes y las prácticas juveniles, en el sentido que es un ejercicio reflexivo que problematiza y discute con los enfoques posmodernos que diagnostican el fin de lo social y el triunfo de un neo-individualismo. Dado que su diagnóstico apuntaba a que dichas transformaciones de lo social implicaban la emergencia de nuevos modos de estar juntos, donde se recombinan -simultánea y heterodoxamente- temporalidades, espacialidades y elementos propios del mundo antiguo-precolombino, la modernidad y la era digital. Es más, este enfoque señala que, frente al individualismo imperante de las sociedades modernas, el neotribalismo permite romper con éste y reconstruir -por la vía de las redes y la unión de punteado- los lazos comunitarios, pero dicha recomposición supone -para esta nueva fase- mayor plasticidad, porosidad, movilidad, autonomía y reconocimiento de lo singular, espontaneidad, energía emocional, horizontalidad, translocalidad, colaboración rizomática y participación activa, democratización en todos sus niveles, etc.

Esto genera adscripciones y críticas a esta postura teórica. Autores como Nateras (2004), señalarán que esta perspectiva entendida como una metáfora que fue muy influyente, y que para nosotros sigue siendo, permite dar cuenta de una alta diversidad y heterogeneidad de los agrupamientos de los jóvenes, cuestión que no era posible entender antes de la aparición de este concepto, donde sólo primaban visiones dicotómicas de las prácticas juveniles. Sin embargo, invisibilizaban ciertas cuestiones, como la participación de las jóvenes mujeres, cuestión que habría que señalar ya venía siendo criticada en los estudios culturales a finales de los años 70'y principios de los 80' (Beezer, 1994). Por otra parte, Reguillo (2008), señala que había que poner atención, a una cierta fascinación con un cierto nomadismo romántico y un tribalismo radicalizado, donde se podía construir un yo aislado e ensimismado, valente por sí mismo pero que se podría percibir inadecuado para los jóvenes, construyendo así, una narrativa precarizada dejando de lado la responsabilidad de las instituciones en esas construcciones.

Sin ahondar, señalamos que estamos de acuerdo con estas críticas y otras que se visibilizaron, las cuales tampoco han sido demasiadas en volumen, dado que, si se revisa la escritura realizada, siempre se dejó en claro que las categorías utilizadas correspondían a metáfora(s) para trabajar las realidades juveniles en nuestro país por lo que, se estaba en una disputa teórica respecto a la conformación de un campo, por lo tanto, las criticas como las defensas, se enmarcan en esa disputa, y como sabemos en nuestras ciencias sociales, las disputas teóricas 
no se resuelven simplemente por el número de críticas o de defensas, sino por la adherencia a las diferentes perspectivas que otros/as investigadores/as realicen, en cuanto le hacen sentido, o bien, lo que marca y define la agenda de investigación en un momento dado.

\subsection{Ajustes de cuentas, balbuceos y metáforas}

Como lo venimos planteando, a finales de la década del 9o’ e inicios del siglo XXI, publicamos una serie de textos a modo de balance de los años 9o' sobre la condición juvenilis, donde pusimos en juego el uso explícitamente metafórico de la noción de neotriblización para leer y comprender un enjambre emergente de colectivos y prácticas generacionales, consumos rituales y estilos urbano-juveniles, altamente performativos y visibles en los espacios públicos de las ciudades, y que rápidamente llamaron la atención de la agenda noticiosa de comienzos del siglo XXI, presentándolos posteriormente como expresiones espectaculares, la mayoría de las veces con el sesgo adultocéntrico de la moda juvenil, o bien, como expresiones de riesgo, desborde y amenaza al orden público, como fue el caso de las llamadas barras bravas, la proliferación de colectivos universitarios o las micro-culturas más radicales como los punk, los skinhead, los okupas, etc. de fuerte anclaje barrial y territorial. Contrariamente a lo que se ha venido escribiendo recientemente por parte de algunos cientistas sociales que también están en el campo de estudios sobre juventudes en Chile, lejos de cualquier operación mecanicista, la denominación de tribus urbanas como forma de entender ciertos tipos de prácticas culturales juveniles, que también podrían denominarse culturas juveniles, y su consecuente aplicación al escenario chileno de aquel momento, obedeció a una adaptación de las conceptualizaciones y matrices interpretativas propuestas por autores como Reguillo, Feixa o Maffesoli a la realidad local; lo que posteriormente y al interior de las discusiones colectivas que se desarrollaron en el CESC, denominamos como "giro cultural" al interior de los estudios de juventud en Chile.

Mirado con la perspectiva y la serenidad que otorga el tiempo, creemos que amerita calibrar estas críticas, algo apresuradas y con escasa perspectiva histórica, que realizaron a este esfuerzo hermenéutico que pusimos a jugar recién iniciado el siglo XXI.

El año 2005 y el 2007 se planteó que el enfoque ligado al "giro cultural" poseía (a) "una débil vinculación con las realidades juveniles estudiadas y con las condiciones de vida de estos jóvenes"; en segundo lugar, (b) se alude a que existiría "una utilización mecanicista de las nociones de neotribalidad y tribus urbana"; (c) que la noción de tribus urbanas tiende a "homogenizar la diversidad a la que apela"; y (d) que dicha noción aún no muestra ni pertinencia ni "rendimiento político" para nuestras realidades locales y regionales (Duarte,

13 Entre los más emblemáticos, 1999 y 2002. 
2005 y 2007).

Como si nada hubiera cambiado en Io años, estos enfoques -a modo de mantra- insisten sobre lo mismo el año 20I5, reeditando exactamente las mismas críticas, únicamente se innova haciendo alusión al carácter "ahistórico y eurocéntrico de estos modos de análisis" (Duarte, 20I5). Luego, se parafrasea a M. Margulis \& M. Urresti para aludir a que las miradas centradas en los símbolos de la cultura evidencian cierta fascinación de quienes analizan, al punto que se les dificulta ir más allá de esa expresividad, quedando atrapados en miradas que no problematizan el tipo de sociedad en que éstas se inscriben (Duarte, 20I5). Otra corriente dentro de este mismo enfoque, emulando las críticas que surgieron los años 2005 y 2007, se plantea en los mismos términos, sumándose al mantra sobre el giro cultural (Aguilera, 2009 y 20I5).

Pero vamos por parte, en primer lugar, se observa una cierta desprolijidad al momento de hacer estas críticas, dado que todos estos juicios discuten e interpelan a un interlocutor equivocado, esto es, un texto menor publicado tardíamente el año 2005, "Juventud la Diferencia como Consigna", en rigor -aclaramos- una compilación de artículos evidentemente heterogéneos y sin la más mínima pretensión de vertebración epistémica de los mismos, donde escriben autores como Duarte, Aguilera, Matus, etc.

Con todo el cariño que le tenemos a dicha compilación, no podemos calificarla como emblemática en los estudios de juventud chilenos. Como en el cine, hay películas que marcan a fuego, otras de las cuales se puede prescindir. Ahora, de lo que no se puede prescindir -a nuestro juicio- es de un libro pionero y capital en los estudios de juventud chilenos ${ }^{14}$, que escribimos el año 200I-2002, y que en nuestra experiencia y trayectoria nos ha permitido sostener diálogos, puentes y lenguajes intergeneracionales de valioso rendimiento, sobre todo con estudiantes y activistas juveniles de diverso linaje. Como muchos/as lo saben, nos referimos en rigor a "Culturas Juveniles, Narrativas Minoritarias, Estéticas del Descontento". Sin embargo, este texto que muchos/as definen como capital y pionero, con sus aciertos y desaciertos, ha sido referenciado muy marginalmente en la bibliografía que ocupan estos autores, menos citado o discutido en su textura o en la episteme que pone en juego (por lo menos en lo que alcanzamos a pesquisar desde la fecha de su publicación hasta el año 20I7).

En segundo lugar, para ser justos, identifiquemos algunas claves relacionales de este texto que se publicó en octubre del año 2002: Sobre la supuesta debilidad con las realidades juveniles estudiadas y con las condiciones de vida de estos jóvenes: aclaramos que para el contexto en cuestión hicimos trabajo de calle y de campo etnográfico en poblaciones como la Legua, Villa Francia, Barrio Franklin, la José María Caro, Quinta Normal, etc. interactuando con

14 Sobre este punto consultar: Matus, Ch. (2015). Presencias, ausencias, encuentros y desencuentros entre culturas y mundos juveniles en el campo simbólico de los estudios de juventud. Última Década, (43) Valparaíso, Chile. 
diferentes raperos y sus redes territoriales, generando datos y relatos que articularon las condiciones de vidas de estos jóvenes con sus estilos y expresiones culturales, de hecho la densidad territorial presente en sus enclaves espaciales, la mayoría altamente estigmatizados y segregados, se constituyen en detonante para la conformación de la identidad y el estilo colectivo, ensamblándose lo biográfico con lo estructural (Zarzuri \& Ganter, 2002).

Sobre la supuesta utilización mecanicista de las nociones de tribus urbanas y el enfoque supuestamente eurocéntrico: resulta completamente frágil esta crítica si uno lee con rigor el mentado libro, dado que lo que se desprende del texto es una apropiación decolonial no solo del enfoque de Maffesoli, sino también un uso decolonial de las metodologías aplicadas. Y qué mejor antídoto para el mecanicismo y el colonialismo intelectual que historizar la condición juvenil y a los actores que nos colaboraron en dicha investigación. Para ello elaboramos una lectura original -a nuestro juicio- que ensambló las hipótesis de la neotribalización juvenil con la historia social de Gabriel Salazar ${ }^{15}$, el postestructuralismo y los planteamientos que Tomás Moulian venía realizando desde

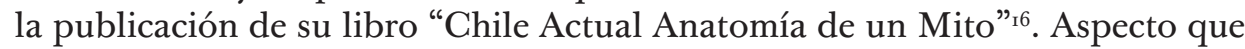
retomamos más adelante.

Sobre la supuesta tendencia a "homogenizar la diversidad" mediante la utilización de la noción de tribus urbanas: no podemos ser ingenuos, ciertamente es un riesgo al cual estamos todos/as expuestos en ciencias sociales, dado que al realizar un corte de la complejidad social que estudiamos, al momento de nombrarla, comprenderla y construir nuestros "objetos-sujetos" de estudio, existe la tendencia a encapsularla, perdiendo riqueza la multiplicidad y el dinamismo de la experiencia vivida. Es lo que ha ocurrido con categorías como las de clase social, lo popular, el pueblo, la propia categoría de juventud, etc. Más aún, en el caso de las tribus urbanas, cuando la publicidad o la industria cultural y mediática la integra a su gramática, codificando su espesor, movilidad y variedad. Sin embargo, se agradece esta crítica, dado que nos da el pie forzado para hacer la aclaración, ya que en su momento no se entendió lo que proponíamos (o no se quiso en entender, invisibilizando un esfuerzo académico honesto y original, plasmado en el suscrito libro del año 2002).

En el texto del año 2002 y del año 1999, utilizamos la noción de tribus urbanas no tanto como una categoría sociológica clásica, sino más bien como una metáfora, una evocación capaz de dar cuenta de la cristalización de nuevas socialidades juveniles de época, donde se mezcla -interclasistamente e intergeneracionalmente- lo comercial, lo masivo y lo alternativo; con lo popular y

15 Quién prologa el libro "Culturas Juveniles, Narrativas Minoritarias" de octubre del 2002; y que posteriormente también utiliza la hipótesis de la neotribalización en el tomo V de su Historia Contemporánea de Chile: Juventud e Infancia; que aparece en diciembre del año 2002. Nos alegró su validación.

16 Revisar para este punto el apartado del libro: "Con-texto Local. Un diagnóstico para el fenómeno juvenil en el Chile contemporáneo" (Zarzuri \& Ganter, 2002); pp. 35-52. 
lo contrahegemónico, lo local con lo global, lo subjetivo con las condiciones sociales de existencia. El proceso de neotribalización juvenil abarcó una gama muy heterogénea de expresiones, desde colectivos de raperos populares que se multiplicaban en barrios y poblaciones estigmatizadas de las principales ciudades de Chile, pasando por expresiones estilísticas "clasemediereas" ligadas con alguna corriente cultural y/o musical, grupos organizados en torno al ocio festivo, hasta colectivos universitarios micro-políticos y culturales de diverso interés. Juventudes y complejidades culturales, por cierto, tanto en lo formal como en lo estructural de sus vidas cotidianas; todas estas socialidades: politeístas, parciales, fluctuantes, porosas, abiertas al juego de las identificaciones postmodernas y las máscaras, más que al de las identidades fijas y esencializadas (Zarzuri \& Ganter, 2002, Ganter \& Zarzuri, 1999).

Tanto reconocíamos las limitaciones de dicha noción que, apelando explícitamente a una "sociología balbuceante" (Zarzuri \& Ganter, 2002), la ocupamos con mayor precaución después del año 2005. Más aún, desde que leímos tempranamente el prólogo de Maffesoli al texto de Feixa sobre "Jóvenes, Bandas y Tribus" en el año 1998, tuvimos plena conciencia que la expresión de este socius en estado puro, como se le llamó, tenía sus días contados, ya que su función fue anunciar un tiempo que nacía y simultáneamente otro que moría: "las tribus postmodernas son cementerios para una ética estética (...) es posible que todo ello presida el alumbramiento de una nueva manera de estar juntos" (Maffesoli, r998, p. 6).

Sobre la supuesta impertinencia del enfoque para leer la realidad local y la noción de neotribalización que no le permite obtener un "rendimiento político" y puentes con otros grupos generacionales: creemos es el más apresurado de los juicios, dado que cae por el propio peso de la historia y los acontecimientos desatados en el Chile reciente. Pero antes de entrar en materia, vale la pena hacer algunas referencias parciales a dos capítulos del libro "Culturas Juveniles, Narrativas...", que ante todo trabajan las relaciones de poder "sobre" y "desde" la condición juvenil ${ }^{17}$. Primeramente se aborda la disputa en el Chile tardopinochetista en torno a la cuestión de la memoria, estos es, las relaciones antagónicas y conflictivas entre memoria oficial y las narrativas contrahegemónicas que ponen en juego las memorias juveniles, particularmente a través de formatos y lenguajes como el rap y otros géneros musicales de fuerte acento generacional, avanzando hacia la pregunta por los sentidos de futuro que allí se fraguan y las consecuentes herencias y discontinuidades entre los imaginarios de los grupos generacionales de los años 6o', los 80' y los 9o'. En el último capítulo se aborda, contrariamente a la creencia de que culturas juveniles y movimientos sociales van por carriles diferentes, el rol que juegan los afectos, las pasiones y las emociones colectivas en la construcción de una nueva poli-

17 Consultar: “La máquina del recuerdo”, pp. 129-170; y “La máquina en Fuga”, pp. 171-191 (Zarzuri \& Ganter, 2002). 
ticidad, ensamblando nuestras evidencias con las hipótesis de autoras como Rossana Reguillo, Maritza Urteaga o Michel Maffesoli ${ }^{18}$.

El historiador Víctor Muñoz Tamayo, sintetiza de modo ejemplar estos postulados: "Con estos atributos postmodernos centrados en las subjetividades y los afectos, las nuevas culturas o tribus juveniles, como el hiphop poblacional santiaguino que se aborda en la investigación, generarían (...) de acuerdo a Zarzuri y Ganter, micro resistencias expresadas en «estéticas del descontento» que contendrían una discursividad orientada a mantener distancias existenciales con lo estructural sistémico (hegemonía de la globalización neoliberal), generando realidades alternas a nivel de las sociabilidades. Se trataría de resistencias expresivas que se anteponen a la estigmatización social y a la invisibilización de una diferencia que, en el caso del hip hop de los pobres, constituye la respuesta cultural de los sujetos excluidos del modelo socioeconómico. Ante un orden de apariencia inamovible, o petrificado, se desarrollaría este movimiento a nivel de lo «subterráneo» o «microfísico», hacia donde, según estos autores, habría que orientar las miradas para conocer las expresiones sociales germinales de nuevos sentidos de lo político, lo privado, lo colectivo y lo emancipatorio: una nueva politicidad" (Muñoz, 2006).

De modo que, si se leen los textos y se usa la literatura de rigor, con la perspectiva y la serenidad que entrega el tiempo histórico, el "pánico moral" hacia "la preminencia del símbolo y la fascinación por lo espectacular en desmedro de lo estructural" (Duarte, 20I5), queda completamente desbaratado. Pero más allá de cualquier malentendido, miopía o invisibilización selectiva de ciertos textos, la hipótesis que aquí queremos esgrimir con relación a las tribus urbanas de los años 9o', y a modo de balance histórico, es que dicha noción no obedeció a un efecto de fascinación sino a un efecto de mediación cultural e histórica.

\section{MEDIACIONES Y ENLACES GENERACIONALES COMO RENDIMIENTO DEL GIRO CULTURAL EN LOS ESTUDIOS DE JUVENTUDES ACTUALES}

Respecto de este punto, vamos a sostener que, a partir de la perspectiva que otorga la mirada histórica de los procesos sociales y el giro cultural y, siendo coherentes con el uso que hiciéramos desde el año i999, del enfoque propuesto por los Estudios Culturales de Birmingham, nuestra aspiración fue intentar mediante el análisis de los significados y valores concretos, identificar pistas sobre las corrientes subterráneas de la historia; las causas generales y las tendencias estructurales que se escondían tras las apariencias de una vida cotidiana (Heb-

18 Por si fuera insuficiente, referenciamos sobre la materia otras contribuciones escasamente referidas por los estudios en juventud chilenos actuales: Ganter, R. (2003) “Micropolíticas de lo Juvenil y Saberes Inconclusos", en Richard, Nelly "Revisar el pasado, criticar el presente, imaginar el futuro", Ediciones Universidad Arcis, Santiago de Chile. Ganter, R. \& Zarzuri, R. (2005) “Metamorfosis de lo político - cultural y colectivos urbano juveniles emergentes”, en Sepúlveda, M. "Nuevas Geografías Juveniles, Ediciones Universidad Diego Portales. 
dige, 2004). Así, lo que se denominó "tribus urbanas" mostraba una expresión concreta de una socialidad juvenil subterránea de carácter procesual inscrita en los años 9o' de la postdictadura, pero que venía manifestándose desde inicios de los años ochenta-. Ella operó como una mediación ${ }^{19}$ en dos niveles: uno de carácter interpretativo y otro de carácter vivencial ente mundos juveniles diversos, es decir, entre un tiempo histórico definido por la fase final de la dictadura cívico-militar y otro definido por el consenso político y la profundización del modelo neoliberal implementado por los gobiernos de la Concertación iniciado el siglo XXI; entre la llamada generación del recuento, de los años 8o' y la generación pingüina del año 2006.

En el nivel interpretativo, la neotribalización juvenil nos sirvió para generar un rendimiento explicativo para la coyuntura juvenil de la postdictadura, evitando entrar en la lógica binaria que caracterizó los estudios en juventud chilenos, por lo cual resultó -a nuestro juicio- más eficiente y pertinente usar esta noción en lugar de hablar de una generación de los "descuentos", del "potente silencio de los años 9o", o bien, de seguir homogeneizando a los jóvenes bajo el rotulo de "jóvenes populares" o "empobrecidos", dado que muchos de ellos y ellas no se auto-percibían de ese modo y las realidades juveniles ya estaban siendo mucho más diversas y complejas que aquel reduccionismo. Así, consideramos la neotribalización juvenil como un ecualizador de expresiones caleidoscópicas -tanto en lo estético como en lo orgánico- de un tiempo que nace y otro que muere, germen -quizás sí, quizás no- de otra sociedad, de otras maneras de estar juntos; signos y sonidos -muchos de éstos ambiguos- de un "enlace generacional" (Mannheim, I993, González, 2003, Muñoz, 20II).

Por otra parte, retomando la lectura que hicimos de Gramsci, bajo las coordenadas de los Estudios Culturales Británicos, nos dimos cuenta en el año 2002 de la importancia de re-vincular lo social, lo político, lo cultural y lo simbólico para leer la cuestión juvenil de fines del siglo XX en Chile, ya no como "anomia", "pánico moral”2o, "niahísmo", "consumismo", "hedonismo" o "desintegración social", sino como resistencias de diverso tipo, desacatos caleidoscópicos que expresaban en la base una progresiva crisis de autoridad -"hegemonía"- de las generaciones adultas y un descontento con el ethos del consenso concertacionista que dominó, durante la llamada transición política, en distintos contextos institucionales (familia, escuela, religión, medios, empleo, partidos,

19 Aquí vamos a entender mediación en los términos y usos que la teoría de la comunicación de J. Martín-Barbero (1991) le otorga, esto es, como articulación, interconexión y negociación entre relaciones supuestamente opuestas o problemáticas. En nuestro caso entre dos generaciones juveniles emblemáticas, entre dos movimientos sociales determinantes en la historia del Chile reciente.

20 Uno de los primeros hitos de este período que encarna estas representaciones de la generación dirigente, fue la Carta Pastoral del Arzobispado de Santiago el año 1991, donde figuraban capítulos como: El sentido de la sexualidad humana y su desfiguración; Tendencias actuales a la inmoralidad; etc. 
política, estado, etc.). Entrado el siglo XXI, la crisis de hegemonía, por lo menos su expresión cultural, se haría más crónica y patente en Chile, decantando fenómenos de desafección, desconfianza generalizada hacia las instituciones y un profundo malestar social (PNUD, 1998, 2002, 2012).

En el nivel vivencial, sostenemos que la neotribalización juvenil de la postdictadura operó como mediación generacional entre el polo expresivo-bohemio (Urteaga, 20II) que participó de la generación joven de los años 8o', cuya épica fue derrocar la dictadura de Pinochet, recuperar los espacios de libertad y la democracia, pero incluyendo repertorios de acción colectiva más festivos y lúdicos que de carácter auto-flagelante ${ }^{21}$; y las corrientes más expresivas y activistas (Urteaga, 20II) que formaron parte de la generación pingüina del año 2006, cuya épica no gravitó exclusivamente en torno a lo "sectorial", la recuperación de la educación pública de calidad, los límites a la desigualdad y la segregación educacional, el rebaje del pase escolar, la desmunicipalización o la derogación de la Ley Orgánica Constitucional de Educación (LOCE), sino que -afirmativamente- en favor de la autonomía del movimiento respecto de los partidos políticos, las orgánicas horizontales, la democracia de base, etc. por tanto, la puesta en escena de una nueva subjetividad política generacional. Paradójicamente, el mundo adulto percibía a este segmento juvenil como un segmento profundamente "afectado" por la "desafección" política; cuando en rigor se trataba de una despartidización de la política.

Con el avance de la normalización democrática, el carácter cultural y político que había mostrado la fiesta a finales de los 8o' se modifica, adquiriendo nuevas manifestaciones y lógicas de gestión. Asociado con lo anterior, por esta época se va consolidando un sentimiento generalizado en los jóvenes de desafección con la forma de hacer política que dominó el momento de la transición: el consenso, la transacción, la política de oficina y en la medida de lo posible. Se releva entonces el rol del grupo de pares, la participación en ámbitos de la vida cotidiana, las relaciones cara a cara y los modos de organización informales, no sujetos a estructuración jerárquica. El reconocimiento juvenil adquiere gran importancia, particularmente el "carrete", donde se observa una reagrupación juvenil por abajo, subterránea, en los bordes del sistema normativo y convencional. Las juventudes se dispersan horizontalmente cubriendo el territorio con redes, colectivos, bandas musicales, "tribus urbanas" (Ganter y Zarzuri, 1999),

21 Para profundizar estas hipótesis revisar: Ganter, R. (2017b). Trayectorias e inflexiones en el espacio de ocio festivo juvenil en la ciudad de Concepción. Última Década, (46); Valparaíso; donde se identifican y describen las primeras expresiones de neotribalización generacional de fines de los 70' y comienzos de los 80' en Chile, particularmente asociadas con el circuito under que transitó entre el Garaje Matucana, el Galpón Trolley, calle Aguilucho en Ñuñoa, etc. Posteriormente el surgimiento de las fiestas Spandex en los 9o' y la discoteque Blondie o el bar Cariño Malo en Concepción; toda una marea de reagrupamiento juvenil, afectivo, vivencial y expresivo por abajo, hasta su diversificación y multiplicación a fines de los 9o' e inicios del siglo XXI en las principales ciudades chilenas. 
barras bravas y otras expresiones. Esto sucede porque los jóvenes necesitaban re-crear socio-emocionalmente un nosotros, donde la cultura de la fiesta y el carrete constituyó una forma de re-agrupamiento juvenil "por abajo" y de sociabilidad entre pares, abierta, interclasista y que cumplió funciones de ajuste intersubjetivo para reconstruir espacios, vínculos, confianzas y afectos colectivos (Contreras, I996; Ganter y Zarzuri; I999; Zarzuri \& Ganter, 2002; Salazar, 2002, Ganter, 2017b).

\section{CONTRIBUCIONES (SIEMPRE DISCUTIBLES) DE LA MIRADA CULTU- RALISTA AL ESTUDIO DE LAS JUVENTUDES EN CHILE}

A nuestro entender, el giro cultural que propusimos en el texto del año 2002 "Culturas Juveniles, Narrativas..." nos permitió plantear que estas expresiones, vinculadas con la neotribalización juvenil, poseían un potente rendimiento, ya que daban cuenta de una transición histórica entre:

Unas formas tradicionales de experimentar la participación sociopolítica hacia otras formas que están empezando a proliferar por el Gran Santiago y que estaría asociada a las denominadas tribus urbanas y/o colectivos juveniles urbano-culturales; como son los casos emblemáticos de colectivos como: Hip-hoplogía, la Surda, los Okupas, los Objetores de Conciencia, etc. (...) Lo anterior estaría ligado -en opinión de autores como Moulian, Salazar y Guattari- a una cierta renovación de la sociedad chilena a partir de su tejido molecular, es decir, una reconfiguración de lo social que habla de la emergencia de nuevas prácticas sociales, nuevos modos de vida y nuevos valores, pero que aún no alcanzan a cristalizar en estructuras más formales, aunque se puede intuir que el objetivo de estos colectivos juveniles tampoco se orienta a la estandarización de sus redes y menos en los términos que prevén las organizaciones sociales tradicionales y los modos de gestión política instituidos desde la cultura adulta. En ese sentido, tanto Moulian (1998) como Guattari (1998) aluden a la "hipótesis" referida a una sociedad petrificada a nivel de sus estructuras, pero con una fuerte reconfiguración sociocultural a nivel de su tejido molecular, a partir de la cual comienza a reivindicarse el espacio de lo localizado en oposición a lo total. Es decir, aun cuando la historia global aparece congelada, existiría -subterráneamente- un invisible y lento proceso de reconstrucción del tejido social, de producción y proliferación de sujetos y actores de nuevo tipo, una rehistorización molecular ligada con el campo de la vida cotidiana. En ese mismo sentido, Salazar (1999) sostiene que la sociedad chilena no deja de ser una sociedad dinámica, expuesta a conflictos y fuertes cambios, aunque dichos procesos -profundos y subterráneos- no tengan un impacto visible e inmediato en el espacio público, en las estructuras e instituciones de la sociedad, pues existirían ciertos cambios asociados a procesos intersubjetivos, es decir, transformaciones internas de los propios sujetos y que, por cierto, se expresan mucho más significativamente en el campo cultural -donde se recrean las me- 
morias colectivas sumergidas- que en el campo de la política oficial (Zarzuri \& Ganter, 2002, pp. 37-38).

La mirada culturalista también nos permitió observar -y nos sigue permitiendo- la trayectoria de las nuevas manifestaciones juveniles que se venían visibilizando y la capacidad de recrear y reconfigurar las socialidades juveniles, sus formas de participación entre otras cosas. Así, si analizamos por ejemplo la generación pingüina del año $2006^{22}$ desde esta perspectiva, veremos una presencia importante de sensibilidades, repertorios de acción colectiva, dinámicas de organización, imaginarios sociales, corrientes culturales que se fraguaron en la postdictadura. La evidencia refiere a la conformación de un socius en los años 9o', como ya lo advirtiera Maffesoli (I990), que se manifestó a partir de una lógica de redes cotidianas, una unión de punteado desjerarquizada, donde la fuerza de los vínculos se fue definiendo por su fragilidad y porosidad; por el predominio de formas lúdicas y expresivas de socialidad; por una potencia afirmativa subterránea; por un reagrupamiento con predominio de la fisicalidad y emocionalidad de la experiencia; por la horizontalidad, la autonomía y descentralización de sus modos de estructuración. Esto mismo es planteado por Gabriel Salazar -sobre la generación de los noventa- releyendo a Maffesoli:

Aunque no tengan sociedad, tienen el instinto de generar sus propios espacios de participación. Lo que equivale a tener el principio generador de toda nueva sociedad (...) lo que prolifera entre los jóvenes son espacios participativos y no organizaciones, la participación subordina la representatividad (...), la tribalización es un fenómeno social complejo, extenso, autónomo e impulsado por una horda de identidades autopropulsadas (...) un fenómeno estratificado: en su base se hallan grupos de pares (...) en un estrato intermedio se ubican los colectivos universitarios (...) en un estrato de mayor protagonismo activo, operan las redes y coordinadoras (Salazar, 2002, pp. 262-264).

Cuestiones que ilustra muy bien una de las voceras de la Asamblea Coordinadora de Estudiantes Secundarios (ACES), Úrsula Schüler: "Yo venía de toda la subcultura punki anarquista santiaguina a fines de los ' 90 (...) de a poco empezamos a ser mayoría, teníamos hartos colectivos coordinados en distintos liceos (...) fuimos generando una nueva mayoría dentro del activo político secundario" (Domedel \& Peña y Lillo, 2008, p. 50). De modo que, más que la expresión de sujetos/as sujetados/as o sustantivos, se trataba de posiciones de sujetos/as, donde se observa la mezcla heterogénea y porosa de experiencias, biografías, estéticas, géneros, afectos, memorias colectivas, estilos, corrientes políticas, lugares, espacios, discursos, orgánicas, referencias generacionales diversas, etc.

Como es sabido, la generación pingüina estuvo piloteada por estudiantes secundarios de diverso origen social que, más allá de cualquier ideologismo

El CESC realizó un seguimiento al movimiento pingüino a través de la prensa que quedó plasmado en lo que se denominó: "Jóvenes a Diario". Ver: http://cesc.cl/portfolio/jovenes-diario/ 
trasnochado y demanda sectorial, reivindicaban otro modelo educativo para Chile. Pero también se caracterizaron por sostener una profunda desconfianza hacia la clase política y una crítica radical hacia la democracia representativa. Se trataba de una nueva subjetividad política. Esta generación privilegió la democracia de base, no defendían ni al mercado ni al Estado. Pero traían en su memoria colectiva y en sus repertorios de acción colectiva: la autogestión como forma eminente de participación; la acción directa de carácter lúdico-performativa, festiva y creativa; potentes redes y expresiones culturales; aprendizajes en torno a la vivencia de la horizontalidad y la afectividad en sus modos de estructuración; la autonomía respecto de los partidos políticos; escasos líderes, pero compensaban con vocerías múltiples, móviles, revocables; y un profuso uso y gestión descentralizada de redes sociales para difundir su mensaje y coordinar sus acciones colectivas: blogs, fotologs, messenger, etc. (Ganter, 20I7b).

Así, la llamada generación pingüina irrumpe en el siglo XXI portando en su equipaje esta herencia y aprendizajes de la postdictadura, también la del "mochilazo" del año 20or entre muchas otras herencias, pero de manera importante las vivencias generacionales de enlace fraguadas a partir de la neotribalización juvenil de los 9o', que a nuestro juicio se constituyó en mediación entre dos mundos generacionales aparentemente inconexos, en tensión y problemáticos.

Actualmente la perspectiva cultural contribuye a mirar de otra forma, por ejemplo, la participación política y las militancias que comienzan a estructurarse hoy en día en los jóvenes. Así, se releva como un eje relevante en la constitución de las nuevas formas de participación política y de militancias, a la vida cotidiana el retorno de formas afectivas y emocionales en los movimientos sociales y generacionales, lo corporal como territorio político, el ciberactivismo de las nuevas generaciones donde se combina la calle con las redes sociales, las nuevas formas que adopta el autonomismo, etc. (Zarzuri, 2005; Araujo y Martucelli, 2012; Zarzuri, 2015, Ganter, 2017a). Se observa entonces en los jóvenes, que sus adscripciones identitarias políticas ya no se conectan necesariamente con las estructuras partidarias tradicionales, sino con una estructura de vida que posibilita las construcciones de identidades que se constituyen en banderas de participación y lucha política, como lo manifiestan, por ejemplo, los/el: animalista, movimiento gay/lésbico/trans, veganismo, ciclistas furiosos, conservacionista/ambientalista, la reciente marea feminista del 2018 en Chile impulsada -intergeneracionalmente- por estudiantes universitarias auto-convocadas, por fuera de las orgánicas políticas y sectoriales tradicionales, entre otros. Esto se conecta con lo que otros/as investigadores/as señalan al referirse a las formas en que se está articulando la relación jóvenes y política. Las nuevas articulaciones, se corresponden más a lo que es la cultura de los jóvenes hoy en día, pero también a la cultura de la sociedad contemporánea (Pleyers, 2015, Urteaga, 20II; Arditi, 2012; Bonvillani, 2005; Botero, 20II). Emulando al sociólogo chileno Carlos Ruiz (2015), se trataría de un retorno incesante: "De nuevo 
la Sociedad", o bien, "de nuevo otra(s) sociedad(es)".

Por último, uno de los aportes que es posible relevar -con modestia- desde la dimensión simbólica y la mirada sociocultural a los estudios de juventudes en Chile -más que en haber releído localmente los nuevos modos juveniles de estar juntos a través de la metáfora de la neotribalización o incluso en haber desplegado metodologías situadas de indagación en la agenda investigaciónconsistió en promover una crítica epistémica a los enfoques binarios que predominaron en la producción científica chilena del último tramo del siglo XX e inicios del siglo XXI para explicar la subjetividad juvenil contemporánea: lo epidemiológico v/s lo redentor; la satanización v/s la exaltación; la exclusión v/s la inclusión; lo tradicional v/s lo innovador; lo popular v/s lo exclusivo; lo alternativo v/s lo masivo; lo periférico v/s lo central; lo global v/s lo local; lo macro v/s lo micro; lo auténtico v/s lo espurio; lo adultocéntrico v/s lo juvenocéntrico; sujeto v/s estructura; subversivo v/s integrado; nosotros v/s los otros, etc.

Dicha crítica se inspiró y reivindicó, a finales de los años 9o’ en Chile, lo que se llamó el pensamiento rizomático, desarrollado y difundido por autores como Deleuze \& Guattari (I995), en un claro gesto por complejizar y desestabilizar las antiguas certezas y los modos binarios que predominan en occidente para pensar y generar conocimiento; poniendo a jugar elementos y saberes múltiples, conexiones heterogéneas y relaciones -a veces- profundamente problemáticas y conflictivas. Lo que implicaba un giro en el lugar y el modo desde dónde hacer las preguntas, las búsquedas, las exploraciones para aproximarse, acompañar y colaborar con ciertos agrupamientos juveniles. Esto supuso y supone pasar de una lógica del "esto" o "aquello", a una episteme del "esto" y "aquello". Otros, desde los Estudios Subalternos y las corrientes postcoloniales, más recientemente han enunciado dicho lugar como un "in-between" o "entremedio" (Bhabha, H. 2002), espacio donde se intersectan, convergen, tensionan y articular todas las diferencias23.

En el fondo más que comprender sustancias estáticas, el gesto implícito del giro cultural apelaba a comprender -relacionalmente y dialécticamente- las vivencias y condiciones de existencia juveniles a partir de posiciones activas de sujeto, esto es, en tanto agenciamiento juvenil, la mayoría de las veces móviles, fluidos, mestizos y contingentes. Así, se trata de comprender lo que está por debajo del juego lábil de expresividades, de sus máscaras, mediaciones, seducciones, complicidades, articulaciones, tensiones e hibridaciones promiscuas.

El giro cultural en los estudios de juventud chilenos contribuyó -como parte de un desafío que se sostiene y proyecta- a pensar las interacciones y mediaciones entre estructuras y sujetos, entre lo histórico y lo biográfico, entre lo dominante y lo subalterno, gramscianamente hablando, entre lo orgánico y

23 A modo de ilustrar este punto, a nuestro juicio, lo que viene haciendo el rapero Gonzalo Luanko se vincula estrechamente con lo que aquí postulamos. 
lo coyuntural, y donde la noción de hegemonía desempeña un rol central. De ahí que junto con J. Martín-Barbero (I99I), planteamos -para dejar abierto el debate- que "no toda asunción de lo hegemónico por lo subalterno es signo de sumisión como el mero rechazo no lo es de resistencia, y que no todo lo que viene "de arriba" son valores de la clase dominante, pues hay cosas que viniendo de allá responden a otras lógicas que no son las de la dominación (...) la tendencia maniquea a la hora de pensar la "industria cultural" será muy fuerte. Pero paralela a una concepción de esa cultura como mera estratagema de dominación se abre camino otra mucho más cercana a las ideas de Gramsci y Benjamin". (p. 87)

\section{REFERENCIAS}

Aguilera, O. (2009). Los estudios sobre juventud en Chile: coordenadas para un estado del arte. Última Década, (3I).Valparaíso, Chile.

Aguilera, O. y Muñoz, V. (2015). Preguntas por la juventud, preguntas por la política. Acción colectiva, movimientos sociales y militancia en los estudios de juventud. Chile i967-2013. En: P. Cottet, Fuventudes: metáforas del Chile contemporáneo. Santiago de Chile: RIL Editores.

Araujo, K. y Martuccelli, D. (2012). Desafíos comunes. Retrato de la sociedad chilena y sus individuos. Tomo I. Santiago de Chile: LOM ediciones.

Arditi, B. (2012). "Las insurgencias no tienen un plan - ellas son el plan: Performativos políticos y mediadores evanescentes". Sul-Americana de Ciencia Política, I (2), pp. I - I8.

Bhabha, H. (2002). El lugar de la cultura. Buenos Aires: Manantial.

Beezer, A. (1994). Dick Hebdige, subcultura: el sentido del estilo. En: M. Barker A. Beezer (Eds.) Introducción a los Estudios Culturales. Barcelona: Bosch.

Bonvillani, A. (2013). Cuerpos en marcha. Emocionalidad política en las formas festivas de protesta juvenil. Nómadas, (39), pp. 91 - I03.

Botero, P. y Muñoz, E. (20II). Militancias estéticas y contra-comunicativas. Transformación social, memoria colectiva y cultura(s) popular(es). En: M. E. Boito, E. Toro, y J. L. Grosso, (Comps.) (pp. 399-4II).Buenos Aires: Estudios Sociológicos Editora.

Bourdieu, P. \& Wacquant, L. (2008). Una invitación a la sociología reflexiva. Buenos Aires, Argentina: Siglo XXI Editores.

Contreras, T., Guajardo, S \& Zarzuri, R. (2005). Identidad, participación e hitos de resistenciajuvenil en chile contemporáneo. Documento de trabajo: CESC.

Cottet, P. y Galván, L. (1993). Fóvenes: una conversación social por cambiar. Santiago: ECO, Educación y Comunicaciones.

Deleuze, G. \& Guattari, F. (1995). Mil Mesetas. Capitalismo y esquizofrenia. Barcelo- 
na: Paidós.

Domedel, A. y Peña y Lillo, M. (2008). El Mayo de los pingüinos. Santiago de Chile: Editorial Universidad de Chile.

Duarte, C. (2005) Trayectorias en la construcción de una sociología de lo juvenil. En: Personay Sociedad, XIX(3). Santiago: Universidad Alberto Hurtado.

Duarte, C. (2007). Tensiones en el análisis de lo juvenil. En: Nuevos Perfiles Generacionales, 4 (I5), Santiago: Observatorio de Juventud. Instituto Nacional de la Juventud.

Duarte, C. (20I5). Estudios juveniles en Chile: «devenir de una traslación”. En P. Cottet (coord.), Juventudes: metáforas del Chile contemporáneo. Santiago de Chile: RIL editores.

Durkheim, E. (2012). La división del trabajo social. Madrid: Biblioteca Nueva Minerva.

Feixa, C. (I998). Dejóvenes, bandasy tribus. Barcelona: ARIEL.

Fernández, F. (20II). La movida alternativa en Chile. Recuperado de: http://centex.portalpatrimonio.cl/wp-content/uploads/20II/og/Fiestasalternativas-en-Chile.pdf

Ganter, R. (2003). Micropolíticas de lo Juvenil y Saberes Inconclusos. En: N. Richard, Revisar el pasado, criticar el presente, imaginar el futuro. Santiago de Chile: Ediciones Universidad ARCIS.

Ganter, R. (20I5). Consumo cultural juvenil: apuntes y pistas para posibles líneas de investigación en el Chile actual. En P. Cottet, Fuventudes: metáforas del Chile contemporáneo. Santiago de Chile: RIL editores.

Ganter, R., Fuica, I. y Vergara, C. (20I7a). Caleidoscópolis: signos de cambio en los repertorios de protesta callejera en Concepción. Universum. Talca, Chile: Editorial Universidad de Talca.

Ganter, R. y Rivera, A. (20I7b). Trayectorias e inflexiones en el espacio de ocio festivo juvenil en la ciudad de Concepción; Última Década. Valparaíso: Centro de Estudios Sociales CIDPA.

Ganter, R. \& Zarzuri, R. (2005). Metamorfosis de lo político - cultural y colectivos urbano juveniles emergentes. En: M. Sepúlveda, Nuevas Geografías Fuveniles. Santiago de Chile: Ediciones Universidad Diego Portales.

Ganter, R. \& Zarzuri, R. (I999). Tribus urbanas: por el devenir cultural de nuevas sociabilidades juveniles. Perspectivas, (8). Santiago de Chile: Universidad Católica Silva Henríquez.

González, Y. (2003). Existieron una vez setenta y tres muchachos... Paramilitarización y militancia de las juventudes mesocráticas chilenas. JOVENes, (Ig). México: IMJ.

Guber, R. (200I). La etnografía, método, campo y reflexividad. Bogotá, Colombia: Grupo Editorial Norma.

Hebdige, D. (2004). Subcultura: el significado del estilo. Buenos Aires: Paidós.

Hopenhayn, M. (I997). Nuclearse, resistirse, abrirse: las tantas señales en la identidad juvenil. Revista Chilena de Temas Sociológicos, (3). Santiago, Chile: 
Universidad Católica Blas Cañas.

Maffesoli, M. (1990). El tiempo de las tribus. El declive del individualismo en la sociedad de masas. Barcelona: Icaria.

Mannheim, K. (I993). El problema de la juventud en la sociedad moderna. En: Diagnóstico de nuestro tiempo. México: FCE.

Martín-Barbero. J. (1991). De los medios a las mediaciones. Comunicación, Cultura y Hegemonía.. México: Ediciones G. Gili S.A.

Matus, Ch. (2000). Tribus urbanas: entre ritos y consumos. El caso de la discoteque Blondie. Última Década, (13), pp. 97-120. Viña del Mar, Chile: CIDPA.

Matus, Ch. (20oob). Festividad Juvenil Urbana en Santiago de Fin de Siglo: Las Fiestas Alternativas de la Discoteque Blondie. En: F. Sepúlveda y R. Pantoja (eds.), La Fiesta Ritual: Valor Antropológico, Estético, Educativo. Colección Aisthesis, XVI. Santiago, Chile: Facultad de Filosofía-Instituto de Estética, Universidad Católica de Chile.

Matus, Ch. (200I) De la Blondie a Bellavista: dos aproximaciones a los rituales del consumo juvenil nocturno. Polis, (2). Santiago, Chile: Universidad Bolivariana.

Matus, Ch. (20orb). Tribus urbanas en Santiago de Chile: entre ritos y consumos. El caso de la discoteque Blondie. En: S. Donas y E. Mendoza (comps.), Adolescencia y fuventud en América Latina. Costa Rica: Universitario Regional.

Matus, Ch. (2002). Carrete Juvenil y Tiempo Ocioso. Revista Patrimonio Cultural, 7 (26). Santiago, Chile: DIBAM.

Matus, Ch. (2004). El Carrete en Chile. El Carrete como Espacio Cultural Juvenil. En: La reducción de daños y la gestión del riesgo en Europa y el carrete en Chile. Santiago: Ediciones Red Chilena Reducción de Daños.

Matus, Ch. (2005). El carrete como escenario: una aproximación etnográfica a los códigos de la sexualidadjuvenil. Revista CIDPA, (2). Valparaíso, Chile: CIDPA.

Matus, Ch. (2007). Prácticas urbanas para una nueva imagen de ciudad. Una aproximación a la experiencia del ocio juvenil nocturno y la apropiación festiva en la ciudad de Santiago. Acceso Directo, (2). Rosario, Argentina: Centro de Juventud Municipalidad de Rosario.

Matus, Ch. (2015). Presencias, ausencias, encuentros y desencuentros entre culturas y mundos juveniles en el campo simbólico de los estudios de juventud: Una reseña. En: P. Cottet (Ed.) Fuventudes: metáforas del Chile contemporáneo. Santiago: RIL editores.

Muñoz, V. (2002). Movimiento social juvenil y eje cultural, dos contextos de reconstrucción organizativa (1976-1982 / 1989-2002). Última Década, (I7). Santiago, Chile: CIDPA.

Muñoz, V. (2006). Condiciones «Post» y Asociatividad Juvenil: Preguntas por lo Político en México y Chile". Última Década, (25). Santiago, Chile: CIDPA.

Muñoz, V. (20II). Generaciones. Fuventud universitaria e izquierdas políticas en Chile y 
México. (Universidad de Chile-UNAM ig84-2006). Santiago de Chile: LOM ediciones.

Nateras, A. (2004). Trayectos y desplazamientos de la condición juvenil contemporánea. El Cotidiano, 20 (126). México: UAM Azcapotzalco.

Nateras, A. (2014). Vivo por mi madre y muero por mi barrio. Significados de la violenciay la muerte en el Barrio I 8 y la Mara Salvatrucha. México: SEDESOL/INJUVE/ UAM Iztapalapa.

Palma, D. (20I3). Hijos de la trampa. Santiago, Chile: Asterión Ediciones.

Pleyers, G. (20I0). Alter-globalization. Becoming actors in the global age. Cambridge: Polity Press.

Programa de las Naciones Unidas para el Desarrollo (I998). Informe de desarrollo humano en Chile. Las paradojas de la modernización. Santiago, Chile: PNUD.

Programa de las Naciones Unidas para el Desarrollo (2002). Informe de desarrollo humano en Chile. Nosotros los chilenos: un desafío cultural. Santiago, Chile. PNUD.

Programa de las Naciones Unidas para el Desarrollo (2012). Informe de desarrollo humano en Chile. Bienestar subjetivo: el desafío de repensar el desarrollo. Santiago, Chile: PNUD.

Recasens Salvo, A. (I999) Diagnóstico Antropológico de las Barras Bravasy de la Violencia Ligada al Fútbol. Santiago, Chile: Universidad de Chile.

Reguillo, R. (2008). Jóvenes imaginados: La disputa por la representación (Contra la esencialización). Punto Cero, I3(i6).

Ruiz, C. (20I5). De Nuevo la Sociedad. Santiago de Chile: LOM.

Salazar, G. (2002). Historia Contemporánea de Chile. Tomo V: Niñezy fuventud. Santiago, Chile: LOM.

Undiks, A. (I990). Fuventud urbanay exclusión social. Buenos Aires: Ediciones Humanitas y FOLICO.

Urteaga, M. (20II). La construcción juvenil de la realidad. Fóvenes mexicanos contemporáneos. México: Universidad Autónoma Metropolitana - Iztapalapa.

Valenzuela, E. (i984). La rebelión de losjóvenes. Santiago: SUR Ediciones.

Weinstein, J. (I988). Los jóvenes pobladores en las protestas nacionales (Ig83-I984). Una visión sociopolítica. Santiago: CIDE.

Williams, R. (2003). La Larga Revolución. Buenos Aires: Nueva Visión.

Zarzuri, R. (2000). Notas para una aproximación teórica a nuevas culturas juveniles: las tribus urbanas. Última Década, 8 (I3). Viña del Mar: CIDPA.

Zarzuri, R. (200I). Mujeresy microtráfico de drogas. Documento de trabajo. Santiago de Chile: PROSAM.

Zarzuri, R. (2005). Culturas Juveniles y Ciencias Sociales: Itinerarios Interpretativos Transdisciplinares. En: R. Zarzuri y R. Ganter (Comps.), fóvenes: la diferencia como consigna. Ensayos sobre la diversidad cultural juvenil. Santiago, Chile: CESC.

Zarzuri, R. (20I6). Las transformaciones en la participación política de los 
jóvenes en el Chile actual. En: M. A. Garretón (coord.), La gran ruptura. Institucionalidad política y actores sociales en el Chile del siglo XXI. Santiago, Chile: LOM ediciones.

Zarzuri, R. (Ed.) (2012). Jóvenes, participación y construcción de nuevas ciudadanías. Santiago, Chile: CESC.

Zarzuri, R., Aguilera, O. y Contreras, T. (2007). Informefinal estudio sobre participacióny ciudadaníasjuveniles. Santiago de Chile: INJUV/CESC.

Zarzuri, R. \& Ganter, R. (2000). Culturas juveniles y micropolíticas del afecto. Revista Chilena de Temas Sociológicos, 3 (6-7). Santiago de Chile: Universidad Católica Blas Cañas.

Zarzuri, R. \& Ganter, R (2002). Culturasjuveniles, narrativas minoritariasy estéticas del descontento. Santiago de Chile: Editorial Universidad Católica Silva Henríquez. 